\title{
Publisher Correction: Bcl11b is essential for licensing Th2 differentiation during helminth infection and allergic asthma
}

Kyle J. Lorentsen', Jonathan J. Cho1,2, Xiaoping Luo ${ }^{1,2}$, Ashley N. Zuniga1,2, Joseph F. Urban Jr. ${ }^{3}$, Liang Zhou ${ }^{4,5}$, Raad Gharaibeh ${ }^{5,6}$, Christian Jobin ${ }^{5,6}$, Michael P. Kladde ${ }^{5,7}$ \& Dorina Avram², ${ }^{1,5}$

Correction to: Nature Communication; https://doi.org/10.1038/s41467-018-04111-0, published online 26 April 2018

In the originally published version of this Article, the affiliation details for Dorina Avram incorrectly included "Department of Infectious Diseases and Immunology, College of Veterinary Medicine, University of Florida, 2015 SW 16th Ave, Gainesville, FL, 32608, USA", instead of "UF Health Cancer Center, University of Florida, Gainesville, FL 32610, USA". This has now been corrected in both the PDF and HTML versions of the Article.

Published online: 19 July 2018

\begin{abstract}
(c) Open Access This article is licensed under a Creative Commons Attribution 4.0 International License, which permits use, sharing, adaptation, distribution and reproduction in any medium or format, as long as you give appropriate credit to the original author(s) and the source, provide a link to the Creative Commons license, and indicate if changes were made. The images or other third party material in this article are included in the article's Creative Commons license, unless indicated otherwise in a credit line to the material. If material is not included in the article's Creative Commons license and your intended use is not permitted by statutory regulation or exceeds the permitted use, you will need to obtain permission directly from the copyright holder. To view a copy of this license, visit http://creativecommons.org/licenses/by/4.0/.
\end{abstract}

(c) The Author(s) 2018

\footnotetext{
${ }^{1}$ Department of Medicine, Division of Pulmonary Medicine, College of Medicine, University of Florida, 1600 SW Archer Rd, 32610 Gainesville, FL, USA ${ }^{2}$ Department of Anatomy and Cell Biology, University of Florida College of Medicine, 32610 Gainesville, FL, USA. ${ }^{3}$ Beltsville Human Nutrition Research Center, Agricultural Research Service, Diet, Genomic and Immunology Laboratory, US Department of Agriculture, 20705 Beltsville, MD, USA. ${ }^{4}$ Department of Infectious Diseases and Immunology, College of Veterinary Medicine, University of Florida, 2015 SW 16th Ave, 32608 Gainesville, FL, USA. 5 UF Health Cancer Center, University of Florida, 32610 Gainesville, FL, USA. ${ }^{6}$ Department of Medicine, Division of Gastroenterology, College of Medicine, University of Florida, 2033 Mowry Rd, CGRC 461, 32610 Gainesville, FL, USA. 7 Department of Biochemistry and Molecular Biology, College of Medicine, University of Florida, 2033 Mowry Rd., CGRC 359, 32610 Gainesville, FL, USA. Correspondence and requests for materials should be addressed to D.A. (email: davram@ufl.edu)
} 